

records of natural products

\title{
Chemical Composition and Antioxidant Activity of the Seeds Oil of Vitex kwangsiensis C. Pei
}

\author{
Zhenhua Tian ${ }^{\circledR}$ and Xu Liu
}

Marine College, Shandong University at Weihai, Weihai 264209, P.R. China

(Received November 18, 2017; Revised January 28, 2018; Accepted February 05, 2018)

\begin{abstract}
The chemical constitution of the seeds essential oil of Vitex kwangsiensis C. Pei and in vitro antioxidant activity have been investigated. The essential oil was isolated by hydrodistillation method then analyzed by GC-MS. Fifty-six compounds were identified, representing $93.1 \%$ of the oil. The main components identified were methyl linoleate $(11.2 \%)$, caryophyllene oxide $(10.3 \%), \beta$-eudesmol $(9.1 \%)$ and methyl palmitate (8.1\%). The antioxidant activity was tested by DPPH method and it showed weak antioxidant activity. The composition and bioactivity of Vitex kwangsiensis seeds oil are described for the first time.
\end{abstract}

Keywords: Vitex kwangsiensis; essential oil; antioxidant activity. (C) 2018 ACG Publications. All rights reserved.

\section{Plant Source}

Ripe seeds of Vitex kwangsiensis were collected from Jinchengjiang district, Guangxi province, China, and were identified to be the Vitex kwangsiensis by Associated Prof. Hong Zhao of the Marine College, Shandong University at Weihai. The voucher specimen (No. VK201109) is deposited at Herbarium of Shandong University, Weihai. Plant samples were air-dried prior to hydrodistillation.

\section{Previous Studies}

The genus of Vitex contains about 250 species distributed widely in tropical and temperate zones[1,2]. There are 14 species and 7 varieties growing mainly in south of Yangtaze River, China. The Vitex family is traditional Chinese herb that the fruits, leaves, especially seeds were used for healing and recent study showed that the extract possess antitumor, antimicrobial and antioxidant activities[3]. It has been reported that sabinene, 1,8-cineole in the fruits, seeds, flowers of Vitex agnus-castus [4,5]; butylated hydroxytoluene (BHT), phytol, $\beta$-caryophyllene in the leaves of Vitex megapotamica [6]; $\beta$-pinene , $\beta$ caryophyllene and $\beta$-elemene in the leaves of Vitex quinata [7].Vitex kwangsiensis $\mathrm{C}$. Pei is endemic to China and is used for relieving cough and heavy pant. As far as we know, there is no former study on the essential oil of Vitex kwangsiensis seeds and its biological activity.

\footnotetext{
${ }^{*}$ Corresponding author: E-Mail: deanwhite@sdu.edu.cn (X. Liu); Phone and Fax: +86-6315688049

The article was published by ACG Publications 


\section{Present Study}

The ripe seeds of Vitex kwangsiensis (200g) were dried at room temperature. The essential oil was extracted by hydrodistillation in a Clevenger type apparatus for $3 \mathrm{~h}$. The obtained oil was stored at $4^{\circ} \mathrm{C}$ until future tests.

Table 1. Chemical composition of essential oil of Vitex kwangsiensis seeds

\begin{tabular}{|c|c|c|c|c|}
\hline No & Compound Name & $\%$ & RI & Identification Method \\
\hline 1 & 1,8-Cineole & 2.7 & 1035 & RRI,MS \\
\hline 2 & 2-Butoxyethyl acetate & 0.6 & 1087 & MS \\
\hline 3 & 8-Hydroxylinalool & 0.5 & 1105 & RRI,MS \\
\hline 4 & 4-Terpineol & 3.1 & 1186 & MS \\
\hline 5 & $\alpha$-Terpineol & 0.6 & 1198 & RRI,MS \\
\hline 6 & 5-Caranol & 0.9 & 1202 & MS \\
\hline 7 & $p$-Menth-4-en-3-one & 0.2 & 1258 & MS \\
\hline 8 & 2,3-Camphanediol & 0.2 & 1263 & MS \\
\hline 9 & Geraniol acetate & 0.4 & 1288 & RRI,MS \\
\hline 10 & Isoborneol ethyl ester & 2.7 & 1294 & MS \\
\hline 11 & $\beta$-Methylnaphthalene & 0.2 & 1307 & RRI,MS \\
\hline 12 & Elixene & 0.1 & 1347 & RRI,MS \\
\hline 13 & $\alpha$-Terpineol acetate & 1.3 & 1356 & RRI,MS \\
\hline 14 & $\alpha$-Cubebene & 0.3 & 1359 & RRI,MS \\
\hline 15 & $\begin{array}{l}\text { 2-Butanone, 4-(7-methoxy-7- } \\
\text { methyl-2-oxepanylidene) }\end{array}$ & 0.2 & 1369 & MS \\
\hline 16 & Cedrene & 0.3 & 1389 & RRI,MS \\
\hline 17 & $\beta$-Elemene & 0.9 & 1403 & RRI,MS \\
\hline 18 & Cyperene & 0.4 & 1432 & RRI,MS \\
\hline 19 & $\alpha$-Guaiene & 0.1 & 1426 & RRI,MS \\
\hline 20 & $\begin{array}{l}\gamma \text {-Caryophyllene (cis- } \\
\text { Caryophyllene) }\end{array}$ & 3.1 & 1438 & MS \\
\hline 21 & Thujopsene & 0.3 & 1451 & RRI,MS \\
\hline 22 & Ledene & 0.3 & 1455 & RRI,MS \\
\hline 23 & $\alpha$-Himachalene & 0.6 & 1472 & MS \\
\hline 24 & $1 \xi, 6 \xi, 7 \xi$-Cadina-4,9-diene & 1.1 & 1492 & RRI,MS \\
\hline 25 & $\beta$-Selinene & 1.4 & 1506 & RRI,MS \\
\hline 26 & $\beta$-Bisabolene & 2.1 & 1517 & RRI,MS \\
\hline 27 & Eremophilene & 1.3 & 1522 & RRI,MS \\
\hline 28 & $\beta$-Guaiene & 2.2 & 1531 & RRI,MS \\
\hline 29 & $\delta$-Cadinene & 2.7 & 1538 & RRI,MS \\
\hline 30 & $\beta$-Himachalene & 1.9 & 1547 & RRI,MS \\
\hline 31 & Selina-3,11-diene-2,14-diol & 0.6 & 1554 & MS \\
\hline 32 & $\alpha$-Calacorene & 1.0 & 1561 & RRI,MS \\
\hline 33 & Caryophyllene oxide & 10.3 & 1574 & RRI,MS \\
\hline 34 & calamenene & 0.8 & 1581 & MS \\
\hline
\end{tabular}


35 Isoaromadendrene epoxide

\begin{tabular}{|c|c|c|}
\hline 0.8 & 1619 & RRI,MS \\
\hline 1.5 & 1647 & RRI,MS \\
\hline 2.0 & 1660 & RRI,MS \\
\hline 9.1 & 1677 & RRI,MS \\
\hline 1.3 & 1719 & RRI,MS \\
\hline 1.1 & 1753 & RRI,MS \\
\hline 0.4 & 1794 & MS \\
\hline 0.7 & 1805 & MS \\
\hline 0.3 & 1840 & RRI,MS \\
\hline 8.1 & 1924 & RRI,MS \\
\hline 0.2 & 1933 & MS \\
\hline 0.5 & 1945 & MS \\
\hline 0.3 & 1987 & RRI,MS \\
\hline 0.2 & 1993 & RRI,MS \\
\hline 2.3 & 2001 & RRI,MS \\
\hline 0.4 & 2010 & RRI,MS \\
\hline 0.3 & 2020 & RRI,MS \\
\hline 11.2 & 2097 & MS \\
\hline 4.0 & 2101 & MS \\
\hline 0.2 & 2104 & MS \\
\hline 2.5 & 2124 & RRI,MS \\
\hline 0.3 & 2158 & RRI,MS \\
\hline \multicolumn{3}{|l|}{33.3} \\
\hline \multicolumn{3}{|l|}{30.7} \\
\hline \multicolumn{3}{|l|}{23.1} \\
\hline \multicolumn{3}{|l|}{3.1} \\
\hline \multicolumn{3}{|l|}{2.0} \\
\hline 0.9 & & \\
\hline
\end{tabular}

Total

93.1

Concentration calculated from total ion chromatogram; RRI: Relative retention indices calculated against n-alkanes; Identification method based on the relative retention indices (RRI) of authentic compounds on a HP-5 colum; MS, identified on the basis of computer matching of the mass spectra with Nist 1.7 Mass Spectral Database and comparison with literature data.

Yellow oil with a yield of $1.21 \mathrm{~mL} / 100 \mathrm{~g}(\mathrm{v} / \mathrm{w})$ was obtained by hydrodistillation of Vitex kwangsiensis. The chemical constituents in the essential oil are esters (33.3\%), terpenes (30.7\%), alcohols $(23.1 \%)$, ethers $(3.1 \%)$, aromatic compounds $(2.0 \%)$ and ketones $(0.9 \%)$ which together account for $93.1 \%$ of the oil. The major components are esters $(33.3 \%)$ which consist of methyl linoleate $(11.2 \%)$, methyl palmitate $(8.1 \%)$, methyl elaidate $(4.0 \%)$, isoborneol ethyl ester $(2.7 \%)$, methyl stearate $(2.5 \%)$ and other 8 esters. There is a $30.5 \%$ of sesquiterpenens in the oil, including caryophyllene oxide $(10.3 \%)$, $\gamma$-caryophyllene $(3.1 \%)$ and $\delta$-cadinene $(2.7 \%)$ etc. The oil contains alcohols, $\beta$-eudesmol $(9.1 \%)$, 4 terpineol (3.1\%) and manool (2.3\%) are the main component(Table 1). Esters, sesquiterpene and alcohols constitute the $86.9 \%$ of the volatile oil. The main components were methyl linoleate, caryophyllene oxide, $\beta$-eudesmol, methyl palmitate and cubenol. Some main constituents are correspond to previous studies. Caryophylene oxide was detected in the previous study, it varies among species from $2.2 \%$ in the leaves of Vitex agnus-castus to $27.5 \%$, and in Vitex kwangsiensis the content is $11.1 \%$ [4,8]. As well as the $\beta$ - 
caryophyllene content range from $4.6 \%$ in the itex agnus-castus to $21.4 \%$ Vitex negundo $L$, but in our study it was $6.2 \%$ [2,9]. In the previous study, sabinene, viridiflorol, $\beta$-caryophyllene, terpinen-4-ol, epilaurenene, humulene epoxide II, and abietadiene were detected as the major component extracted from 23 populations of Vitex negundo L. from India, but the composition varied depending on the origin [2]. In conclusion, the components of the oil differ in different species, even the same specie are different for the geographical differences.

The ability in quenching the stable radical 1,1-diphenyl-2-picrylhydrazyl (DPPH) was monitoring to evaluated the antioxidant activity of oil [10]. Ascorbic acid was used as the control. A maximum concentration $1 \mathrm{mg} / \mathrm{mL}$ of oil was conducted and the radical scavenging rate was $26.76 \%$, which showed weak antioxidant activity. The main constitute of the oil were fatty acid esters and lack of flavonoids, phenolic and other antioxidative components. The aromatic compounds, sesquiterpenes and diterpenes may contribute towards the antioxidant activity of the essential oil extracted from the seeds of Vitex kwangsiensis.

\section{ORCID}

Xu Liu: 0000-0003-4480-330X

Zhenhua Tian: 0000-0002-7244-9822

\section{References}

[1] F. Senatore, G. D. Porta and E. Reverchon (1996). Constituents of Vitex agnus-castus L. essential oil, Flavour Frag J. 11(3), 179-182.

[2] R. C. Padalia, R. S. Verma, A. Chauhan, C. S. Chanotiya and S. Thul (2015). Phytochemical diversity in essential oil of Vitex negundo L. populations from India, Rec. Nat. Prod. 10(4), 452-464.

[3] O. P. Tiwari and Y. B. Tripathi (2007). Antioxidant properties of different fractions of Vitex negundo Linn., Food Chem. 100(3), 1170-1176.

[4] D. Stojković, M. Soković, J. Glamočlija, A. Džamić, A. Ćirić, M. Ristić and D. Grubišić (2011). Chemical composition and antimicrobial activity of Vitex agnus-castus L. fruits and leaves essential oils, Food Chem. 128(4), 1017-1022.

[5] B. Marongiu A. Piras, S. Porcedda, D. Falconieri, M. J. Gonçalves, L. Salgueiro, A. Maxia and R. Lai (2010). Extraction, separation and isolation of volatiles from Vitex agnus-castus L. (Verbenaceae) wild species of Sardinia, Italy, by supercritical $\mathrm{CO}_{2}$, Nat. Prod. Res. 24(6),569-579.

[6] T. F. de Brum, A. A. Boligon, J. K. Frohlich, T. G. Schwanz, M. Zadra, M. Piana, A. L. Froeder and M. L. Athayde (2013). Composition and antioxidant capacity of the essential oil of leaves of Vitex megapotamica (Sprengel) Moldenke, Nat. Prod. Res. 27(8),767-770.

[7] D. N. Dai, T. D. Thang, I. A. Ogunwande and O. A. Lawal (2016). Study on essential oils from the leaves of two Vietnamese plants: Jasminum subtriplinerve C.L. Blume and Vitex quinata (Lour) F.N. Williams, Nat. Prod. Res. 30(7), 860-864.

[8] R. Tayebee, E. Filehkesh and V. Amani (2007). Study of the oil constituents extracted from leaf, flower and gramineous stipes of Vitex Pseudo-negundo, Asian J Chem. 19(3), 1772-1776.

[9] C. SariKurkcu, K. Arisoy, B. Tepe, A. Cakir, G. Abali and E. Mete (2009). Studies on the antioxidant activity of essential oil and different solvent extracts of Vitexagnus castus L. fruits from Turkey, Food Chem. Toxicol. 47(10), 2479-2483.

[10] N. Nenadis and M. Tsimidou (2002). Observations on the estimation of scavenging activity of phenolic compounds using rapid 1,1-diphenyl-2-picrylhydrazyl (DPPH) tests, J. Am. Oil Chem. Soc. 79(12), 11911195 .

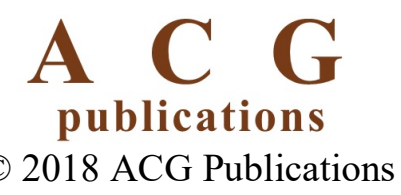

